\section{Fragrant aristocrats}

\section{Leslie Crombie}

The Scent of Orchids: Olfactory and Chemical Investigations. By Roman Kaiser. Elsevier: 1993. Pp. 264. \$175, DFL280.

To most people who buy orchids in the florist's shop it will come as a surprise that a whole book has been written on the subject of these flowers' perfume. This is because we are accustomed to scentless or weakly scented commercial hybrids. Of 2,200 natural species examined, it is estimated that in fact 50 per cent are strongly or moderately scented, with only $15-20$ per cent scentless to the human nose (and even these may not be scentless to an insect pollinator). The monocotyledonous orchid family is the most recent, yet the most extensive, class of flowering plant, with more than 25,000 species subdivided into 750 genera. To most of us, orchids are a class apart, aristocrats of the flower world. No other family excels these plants in range of colour, form and perfume. Roman Kaiser has brought together in this superb book his knowledge and enthusiasm for the botany and ecology of orchids, his skills as a photographer - most of the 170 orchid photographs are his - and his professional expertise as a chemist in the Swiss company Givaudan-Roure, where he has been investigating flower scents in relation to commercial perfumery for many years.

The book is divided into three parts, the first dealing with general information on plant scents, their role in pollination, the way in which orchid scents are collected and analysed without causing damage to the plant, and systems of verbal description of scents. There follows an interdisciplinary account of orchid species, their geography, and flower forms and scents, illustrated by excellent photographs. Finally, there are tables giving the analytical composition of orchid perfumes as determined by head-space analysis using capillary gas chromatography and mass spectrometry.

Scent from orchids is collected by enclosing the flower, passing over it a stream of air, and 'scrubbing' the air with a charcoal filter. According to the circumstances, anything from $1 \times 10^{-6}$ to $3 \times 10^{-4} \mathrm{~g}$ of scent can be obtained by elution from the column with solvent. Gas chromatography separates the components and about $1 \times 10^{-9} \mathrm{~g}$ of each peak fraction must enter the mass spectrometer to get a suitable spectrum.
Mass spectrometry is the most sensitive instrumental detector, yet it is fascinating that the chemist with his nose at the end of a chromatographic column can detect (and sometimes identify) compounds that are in amounts too small to reveal themselves in the mass spectrum. The limits of detection of the human nose are about $10^{-12} \mathrm{~g}$ per litre for a strong odour, and some other animals have much more sensitive organs.

The ecology of orchid scent is also fascinating. In orchids that are mothpollinated, scent is released only at night and complex symbiotic relationships between orchid and insect have been closely honed by parallel evolution. Aristocratic or not, some orchids are prepared to resort to downright fraud. Dracula chestertonii gives off a mushroom scent and the unusually large lip of the orchid imitates the cap of the

\section{Correcting tunnel vision}

\section{Peter Harman}

The Fontana History of Chemistry. By William H. Brock. Fontana: 1992. Pp. 744. $£ 8.99$ ( $p b k)$.

The Fontana History of the Environmental Sciences. By Peter J. Bowler. Fontana: 1992. Pp. 634 . £8.99 (pbk).

THE publication of these accounts of the histories of chemistry and the environmental sciences launches Fontana's new history of science series*. On the evidence of these two volumes, the series will provide accessible yet authoritative surveys, from antiquity to the twentieth century, capped by valuable bibliographic essays that will be of great use to university teachers. The decision to take the story up to the present is especially to be welcomed, and will make the series relevant to students of the sciences; all too often, courses on the history of science are truncated around 1900 because of the paucity of suitable books.

In his preface to the two volumes, the series editor Roy Porter suggests that they should be seen as echoing current perspectives among historians of science, avoiding the anachronism of "tunnel history" (tracing narrowly defined topics through time). The decision to offer volumes devoted to the histories of different scientific fields, spanning more than 2,000 years of historical development, will however strike some historians of science as boldly toying with the pitfalls of anachronism. The problem is clearly understood and confronted by both au-

*The series is to be published in the United States by Norton: The Environmental Sciences and Chemistry are issued next month, each at $\$ 35$ (hbk), $\$ 15.95$ (pbk). mushroom. This induces the mushroom fly to lay eggs while collecting or delivering pollen. When the eggs hatch, the larvae die of starvation through lack of mushroom nutrient. There is no symbiosis here.

The phrase 'coffee-table book' has a slightly derogatory ring and I hesitate to use it for this volume, but its many colour plates reach the best standards of such books. In addition, however, there is a lot of serious interdisciplinary text. So much care has gone into the book's production that it seems almost churlish to point to the occasional slip, as in the formula on page 127. The Scent of Orchids will stand as a landmark book on orchid perfume, while being a pleasure to read.

Leslie Crombie is in the Department of Chemistry, University of Nottingham, Nottingham NG7 2RD. UK. thors: in what sense do 'chemistry' and the 'environmental sciences' have a continuous history since antiquity?

In the case of chemistry, concerned with the properties and reactions of different kinds of matter, the problem is in conceiving the confluence of the various tributaries - metallurgy, pharmacy, dyestuffs, Greek philosophy, alchemy. The status of alchemy especially has long seemed troublesome, forming a decidedly controversial progenitor to the modern science of chemistry. In his recent book Ideas in Chemistry (which I reviewed in Nature 359, 785; 1992), David Knight argues that chemistry has had different and varied characteristics and suggests that its history should be investigated by a study of the ideas that have shaped its development and character. Although Knight's perspective on chemical history is programmatic and lacks the density of Brock's text, his point of view should be borne in mind, for Brock proceeds less circumspectly.

In the case of the environmental sciences, the problem, as Bowler notes, is that the history of the "environmental sciences' may seem to be an "artificial category"; in other words, the definition and unity of the environmental sciences is "not created by the sciences themselves". Here there is the danger then that a very modern perspective - where a science such as ecology has been named only in the past century - seeks to group under a single umbrella modes of scientific inquiry that historically have no unity at all. The answer to the problem surely lies in understanding 'nature' in relationship to different cultural 